\title{
Market efficiency and welfare effects of inter-sectoral water allocation in South Africa
}

\author{
James S. Juana ${ }^{\mathrm{a}}$, Kenneth M. Strzepek ${ }^{\mathrm{b}}$ and Johann F. Kirsten ${ }^{\mathrm{c}}$
}

${ }^{a}$ Corresponding author. Department of Economics, University of Botswana, P/Bag 0022, Gaborone, Botswana

Tel: (267)355 2150/(267)74 5879 82; E-mail: jamessjuana@yahoo.com; james.juana@mopipi.ub.bw

${ }^{b}$ Department of Civil, Environmental and Architectural Engineering, University of Colorado, Boulder, USA

${ }^{c}$ Department of Agricultural Economics, Extension and Rural Development, Faculty of Agriculture and Natural Sciences,

University of Pretoria, Pretoria 0002, South Africa

\begin{abstract}
The need for increased agricultural production to meet the growing demand for food, coupled with concerns for environmental sustainability, economic growth and poverty reduction has increased demand on the already scarce water in South Africa. At the same time, because of agriculture's minimal contribution, compared to the industrial and mining sectors, to South Africa's GDP and employment, the call to reallocate water from agriculture to non-agricultural use has been intensified.

This study updates the 1998 Social Accounting Matrix (SAM) for South Africa and uses the computable general equilibrium model to analyze the impact of water reallocation from agriculture to the non-agricultural sectors on output growth, value added at factor cost, which captures the payments from the production sectors to the factors of production, and households' welfare.

Using different water reallocation scenarios, the simulation results indicate that water reallocation from agriculture to non-agricultural sectors beyond the level of a market allocation scenario will lead to a decline in sectoral output and a significant deterioration in the welfare of poor households. It thus undermines development efforts aimed at reducing the existing level of poverty in the country.
\end{abstract}

Keywords: Computable general equilibrium; Households’ welfare; Sectoral output; Value added

\section{Introduction}

The need to maintain a sustainable environment, economic growth and to increase agricultural production to meet global food requirements has increased the demand for the world's water resources. This has raised concerns about increasing the efficiency of water use. In the last decade, the number of 
countries facing the problem of water scarcity and insufficient water supply has increased sharply. At the global level, while per capita water availability is declining, withdrawals are projected to increase more rapidly, especially in developing countries (Rosegrant et al., 2003). Generally, water scarcity raises two questions: (i) to what extent can water resources be efficiently, equitably and sustainably allocated and used? and (ii) what are the possible ways and means by which water scarcity can be alleviated or mitigated in support of further development? The answers to these questions enable water managers to design appropriate water development policies and allocation strategies.

In South Africa, as the economy grows, the competition for water amongst agriculture, mining, manufacturing industries, and domestic and environmental uses increases, while water supply sources are projected to be inelastic in the future. These factors increase the value of water and, hence, the benefits that could be achieved from efficient water allocation amongst the different sectors.

Table 1 shows that while, irrigation accounts for about $62 \%$ of the total water requirements in South Africa, the agricultural sector contributes only $4 \%$ to the gross domestic product (GDP) and employs only about $11 \%$ of the total number of employees in the country. At the same time, the mining and manufacturing industries which contribute about $8 \%$ and $23 \%$, respectively, to the GDP and employ about $7 \%$ and $19 \%$, respectively, of the total number of employees, account for only $10 \%$ and $5 \%$, respectively, of total water use in the country (DWAF, 2004: 16-18). Thus, there is an economic reason to reallocate water from agriculture to the nonagriculture sectors to promote sectoral water use efficiency. Under efficiency considerations, the issue of reallocating water from low to high-value uses often emerges as rational. In most cases, however, efficiency considerations fail to consider distributional or equity issues. Therefore, the question is not only how much does a particular sector contribute to the GDP but also how can a given water resource be allocated such that the standard of living of the critical mass of people is improved. This justifies the inclusion of welfare considerations into the economic valuation framework. Against this background, this study uses the computable general equilibrium model to critically analyse the impact of water reallocation from agriculture to the non-agriculture sectors on sectoral output, added value, and households' welfare in South Africa.

\section{Data, theoretical framework and modelling procedure}

This section discusses the data and model used in the study. Particular attention is given to the standard Computable General Equilibrium (CGE) conditions, and the behavioural assumptions for the study. It also briefly discusses the transformation of water from a production sector, as recorded in previous CGE models in South Africa, to a factor of production.

\subsection{Description and sources of data}

The study uses an updated version of the 1998 social accounting matrix (SAM) for South Africa which was compiled by Thurlow \& van Seventer (2002). The Trade and Industrial Policy Secretariat (TIPS) 2003

Table 1. Water use, contribution to GDP and employment, by sector (source: DWAF, 2004: 16-18).

\begin{tabular}{llll}
\hline Sector & Water use $(\%)$ & Share of GDP $(\%)$ & Employment $(\%)$ \\
\hline Agriculture & 62 & 4 & 11 \\
Mining & 10 & 8 & 7 \\
Manufacturing & 5 & 23 & 19 \\
\hline
\end{tabular}


supply-use table was used to update the 1998 activities and commodities accounts (TIPS, 2004). Information on household income and expenditure patterns was extracted from Statistics South Africa 2001 census figures (STATSSA, 2004).

The updated SAM was aggregated to 13 activities/commodities consisting of agriculture (AGR), mining (MIN), beverages and tobacco (AGI), textiles and wearing apparel (TEX), wood, paper and printing (PPP), petroleum products (PET), chemicals (CHM), heavy manufacturing (HEV), machinery and equipment (MAC), other manufacturing (OHM), electricity (ELE), construction (CON) and services (SER). These aggregations reflect the structure of water use by these sectors or sub-sectors.

2.1.1. Water. As a key factor in this study, the use of water requires a detailed description of the water data sources and adjustments made to the SAM to properly account for sectoral water allocation and use in the economy. The water supply information from the municipalities' billing records grossly understates the actual water used by the different sectors, because most sectors use self-supplied water. These entries were therefore replaced by the information published in Statistics South Africa water accounts for the nineteen water management areas (STATSSA, 2004). Using the municipal water tariff schedule, the monetary value of the physical quantities of water used by each production sector was computed. This was done to ascertain the resource cost of water used in each sector. Therefore, each water account entry indicates the cost of water used in each sector.

In Thurlow \& van Seventer (2002), water is treated as a production sector, with the row accounts showing water used as a fixed intermediate input by each of the other production sectors and as a final good by households. It also shows payments by these sectors and institutions to the water sector. The column entries show payments by the water sector to the other sectors for the use of other intermediate inputs and factors services. A key objective in this study is to investigate the macroeconomic implications of water reallocation from agriculture to the non-agriculture sectors on the basis of efficiency. Consequently, treating water as a fixed intermediate input (as is usually the approach in standard CGE models) is not suitable. Therefore, water enters into the production process as a third factor of production (a value added function) and not as a fixed intermediate input.

As a factor of production, the row accounts represent distribution of water among the production sectors and the respective payments by these production sectors for the use of this factor. Households initially used water as a final good and made payments to the water sector for this good. These payments are removed from the water accounts and transferred to government which provides the service via its municipal water supply networks. The initial account payments from the other production sectors to the water sector are maintained in the adjusted SAM as payments for the use of this factor. Water no longer pays for factor services as well as for fixed intermediate inputs. To balance the SAM again, the study assumes that all factor payments to water accrue to government, which is recorded as a part of government receipts. This increases government revenue. In its expenditure accounts, government's net investments as well as payments to the services sector increases. This is followed by a corresponding increase in investments in water delivery infrastructure and services payments to the factors of production. The increased factor payments are finally redistributed among the various household categories. Government also pays the rest of the world for the use of water from sources outside South Africa. The adjusted SAM is presented in Table A1 in the Appendix.

The adjusted SAM has three factors of production (water, capital and labour, which itself comprises unskilled, medium-skilled and high-skilled labour). There are also five household accounts (the first to the fifth quintile). Each quintile represents $20 \%$ of the households in that category. Ranked from first to fifth, 
the quintiles represent the least-income, low-income, middle-income, high-income and highest-income households, respectively.

Households receive income from wages and from both local sources (government and inter-personal transfers) and international transfers. Their disposable income is allocated to consumption and savings. Households' consumption is divided into food and non-food consumption. Food consumption is determined by households' expenditure on agriculture and on the beverages and tobacco sectors. Nonfood consumption expenditures are those incurred on the other sectors, which are further divided into durables and non durables. These divisions are the basis for welfare policy investigations. Sectoral output is sold to the production sectors as intermediate input, consumed domestically, or exported. Government accounts, which were broken down into expenditure and income accounts in the original SAM, are maintained.

\subsection{The theoretical framework}

A Computable General Equilibrium (CGE) model is used to investigate the impact of efficient water allocation on households' welfare in South Africa. The study adopts the CGE framework developed by Strzepek \& Carbone (2007). This framework uses the mathematical programming system for general equilibrium (MPSGE), which is GAMS extension developed by Rutherford (1995) (note: the 1995 version is freely available on the website. 1998 version can only accessed within the University of Colorado Campus), with the MCP GAMS solver. MPSGE is a library of functions and Jacobian evaluation routines which facilitate the formulation and analysis of Applied General Equilibrium (AGE) models. The MPSGE program provides a relatively simpler way to write down and analyze complicated systems of nonlinear inequalities. The language is based on nested constant elasticity of substitution utility functions and production functions. The data requirements for a model include share and elasticity parameters for all the consumers and production sectors included in the model. These may or may not be calibrated from a consistent benchmark equilibrium dataset (Rutherford, 1995). The model uses multi-level nested production functions to determine the level of production. Sectoral outputs are represented by a Leontief's combination of fixed intermediate consumption and value added. The model also specifies a constant elasticity of substitution (CES) function to establish the relationship between inputs and output. However, the use of capital is modelled by a Leontief's fixed proportions function, because the short-run use of capital is fixed and sector specific. Conversely, water and the three labour categories are freely mobile across sectors, except where specified. Therefore, the use of these inputs is modelled by the CES function. This allows the functioning of a competitive market to efficiently allocate the mobile factors. Therefore, these mobile factors move to sectors where factor returns are highest. The free movement of these factors of production enhances the adjustment of wages for each of the three labour categories to achieve equilibrium in the factor markets.

The model uses the constant elasticity of transformation (CET) function to formulate the imperfect substitution between domestic consumption of sectoral output and export. The CET function is also used to model the imperfect substitution between domestically produced and imported goods. The imperfect substitutability modelled above enhances the importation and exportation of the same goods.

The factor market for water is closed by assuming that the quantity of water used is fixed and that total sectoral water use is equal to the total sectoral water supply; hence, there are no reserves. The capital and labour markets are closed by assuming that the demand for each of these factors is equal to their supply. These assumptions imply full employment of the factors. The saving-investment closure assumes 
that savings equal investment and that government income (receipts) equals government spending (payments).

\subsection{The experimental simulations}

The situation documented in the adjusted SAM is the base situation which reflects the current sectoral water allocation in South Africa. All input and output prices, including water are normalized in this base period. This situation represents water market inefficiency, because the price paid by the production sectors does not reflect the competitive market price of water.

2.3.1. Scenario 1. To achieve the market efficient level of water allocation, the study uses the sectoral marginal values of water estimated in a related study as shadow prices to calibrate the SAM and allow water use, output, output prices, and input prices to adjust to equilibrium levels. This is referred to as the "market allocation of water". Changes in the indices of output, value added at factor cost, and household welfare under the market efficient allocation of water scenario are all compared to the base indices.

2.3.2. Scenario 2. This is the water reallocation scenario. In this scenario $30 \%, 20 \%, 10 \%$ and $5 \%$ of water in the agriculture sector is reallocated to, and redistributed among the non- agriculture sectors using the computed sectoral marginal values as coefficients. The study then investigates the impact of these reallocations on sectoral output, value added, and households' income and consumption.

\subsection{Analysis of households' welfare}

The study uses the concept of equivalent variation (EV) discussed in Chitiga \& Mabugu (2006) to analyze the impact of the different water reallocation scenarios on households' welfare. EV compares the level of households' consumption at the base prices and incomes to the levels of consumption at the new prices and incomes in the water reallocation scenarios. It provides an estimate of the amount of income (money) that should be given to an individual, a group or an economy to make them as well off as they were before the specified change. In this study the transfer of water from the agriculture sector to nonagriculture sectors is likely to impact the welfare of the different household categories through its impact on factor remuneration and income/consumption. Hence, EV measures the loss of well-being resulting from the income decrease associated with the transfer of water from the agriculture to non-agriculture sectors. Alternatively, it measures the gain in well-being resulting from the income increase associated with the transfer of water from agriculture to non-agriculture sectors.

Functionally, EV is denoted as:

$E V=\left(\frac{P_{1}^{0}}{P_{1}^{1}}\right)^{\gamma}\left(\frac{P_{2}^{0}}{P_{2}^{1}}\right)^{1-\gamma} Y^{1}-Y^{0}$

where $\mathrm{P}_{1}{ }^{0}$ is the price of good 1 in the base model; $\mathrm{P}_{1}{ }^{1}$ is the price of good 1 after the simulation; $\mathrm{P}_{2}{ }^{0}$ is the price of good 2 in the base model; $\mathrm{P}_{2}{ }^{1}$ is the price of good 2 after the simulation; $\mathrm{Y}^{0}$ is the income in the base model and $\mathrm{Y}^{1}$ is households' income after the simulation. 
A positive EV implies welfare improvement (gain), while a negative EV implies welfare deterioration (loss). An increase in households' expenditure or income implies welfare improvement, while a decrease implies welfare deterioration.

\section{Presentation of results}

In this section, the study discusses potential changes in sectoral output, added value and households' welfare that would result from the different sectoral water reallocation scenarios.

\subsection{The impact of water reallocation on sectoral output}

The first block of Table 2 shows the impact of water reallocation on sectoral output. Columns 2 and 3 show the base sectoral output and base indices respectively, and column 4 shows the impact of market allocation of water on sectoral output. The results indicate that the market allocation of water among the production sectors can potentially lead to an overall increase in sectoral output by $6.8 \%$. However, market allocation of water can potentially lead to a significant decline in the output of agriculture, beverages and tobacco, and the services sectors. Columns 5, 6, 7 and 8 show that further reallocation of water from agriculture to the non-agriculture sectors beyond market allocation leads to an overall decline in sectoral output, although output increases in some of the water recipient sectors.

\subsection{The impact of water reallocation on added value}

The alterations in sectoral output have consequences for payments to the factors of production (value added at factor cost). The price of a factor of production is determined by the demand for the factor relative to its supply, which is also determined by the level of sectoral output. Growth in sectoral output leads to a corresponding increase in factor demand, and vice-versa. Since the model assumes full factor employment, factor prices keep adjusting until a competitive equilibrium is achieved. These consequences are presented in the second block of Table 2. Column 2 shows the base factor payments, while column 3 shows the base indices. Column 4 shows the percentage changes in base indices due to market allocation of water, and columns 5, 6, 7 and 8 show the percentage changes to base indices with further reallocation of water from the agriculture to the non-agriculture sectors on the basis of efficiency.

The results show that market allocation of water would potentially increase overall value added by about $11 \%$. Specifically, water tariff increases by about $15 \%$, interest on capital by about $5 \%$, and wages of unskilled, medium-skilled and high-skilled labour by about 9\%,10\% and 12\%, respectively. Although further water reallocation would lead to an overall increase in value added, there are mixed results for specific factors. For example, water tariffs significantly increase for all the water reallocation scenarios. Also, the wages of medium-skilled and high-skilled labour significantly increase, while interest payment on capital and the wages of unskilled labour decline.

\subsection{The impact of water reallocation on households' welfare and agricultural trade}

The alterations in sectoral output as a consequence of sectoral water reallocations on the basis of efficiency, and the implied impacts on value added are transmitted to the various household categories. 
Generally, market allocation of water among the production sectors leads to an overall increase in households' welfare. This is indicated by a positive EV of 1.0439 , which implies a $4.39 \%$ welfare improvement. The simulation results show that further reallocation of water from agriculture to the nonagriculture sectors generally leads to households' welfare improvement, although the welfare of the least and low-income households deteriorates. The third block of Table 2 presents details of the households' welfare implications of inter-sectoral water reallocations. For example, a $40 \%$ transfer of water from agriculture to the non-agriculture sector leads to a $6 \%$ deterioration in the welfare of the least and lowincome households' welfare. On the other hand, the welfare of the middle-income, high and highestincome households improve by $4 \%, 4.6 \%$ and $1 \%$, respectively. The same trend of welfare changes are recorded for the other water reallocation scenarios beyond the market allocation scenario.

Inter-sectoral water reallocation on the basis of efficiency impacts domestic supply of agricultural commodities, agricultural exports and imports. Generally, reallocation of water from agriculture to the nonagriculture sectors leads to a decline in the agriculture sector's output. Consequently, domestic supply of agricultural commodities decreases relative to the demand for these commodities. Therefore, agricultural exports decrease. To meet the domestic demand, agricultural imports increase. For example, when 5\% of the agriculture sector's water is reallocated to the non-agriculture sectors, domestic supply of agricultural commodities decreases by $3.57 \%$, agricultural exports decline by $5 \%$ and agricultural imports increase by $1.32 \%$. All the other reallocation scenarios, including market allocation, show a similar pattern of changes in domestic agriculture supplies, exports and imports of agricultural commodities.

\section{Discussion of research findings, summary and conclusions}

The simulation results show that market allocation of water among the production sectors generally leads to a growth in sectoral output, although agriculture and related sectors' output decline. With the market mechanism, water is reallocated from agriculture to the non-agriculture sectors, because of the low marginal productivity of water in that sector. Therefore, output declines in agriculture due to the decrease of water availability. The output of the sectors that are highly dependent on agriculture as a main source of their intermediate input or as a purchaser of their inputs also decline. With continued reallocation of water beyond the market allocation, total sectoral output falls. This is because the further increase in sectoral water use by these sectors does not lead to a proportionate increase in output.

Alterations in sectoral output due to changes in sectoral water use have consequences for factor remuneration (value added). With alterations in sectoral output, factor prices keep changing until full employment market equilibrium is attained. The prices of factors which are in over supply fall, while the prices of those in excess demand increase. With the market allocation of water, value added at factor cost increases for each of the production factors. However, further reallocation from agriculture to the nonagriculture sectors leads to a decline in total added value. A decrease in agriculture sector's output leads to a decrease in the demand for unskilled labour. To clear the unskilled-labour market, wages decline leading to a decrease in the total wages paid to this labour category. Conversely, the demand for capital, mediumskilled and highly-skilled labour increases more than the supply. Therefore, to clear these markets, their prices increase leading to an overall increase in the added value for these factor categories.

Alterations in sectoral output and corresponding changes in value added at factor costs are transmitted to the various household categories, which are the owners of the resources. With the market allocation, water is utilized efficiently, hence there is growth in sectoral output and value added. This leads to a welfare 
improvement for all the household categories. Although further reallocation leads to an improvement in the overall welfare of households, the welfare of the least and low-income households deteriorates. This is caused by the decline in value added for unskilled labourers due to a decline in the output of the agriculture and related sectors. The main source of income for the least and low-income households are the wages of the unskilled labourers. Therefore, a decline in unskilled labour wages leads to a decline in the income and consumption expenditures of these household categories.

A decline in the agriculture sector's output leads to a decline in domestic agriculture supplies. Therefore, agricultural exports decrease and imports increase to satisfy the domestic demand for agricultural products. In summary, further reallocation from agriculture to the non-agriculture sectors beyond the market allocation level not only leads to a decline in sectoral output but also to a deterioration in the welfare of the most poverty-stricken households.

\section{Acknowledgements}

The authors are grateful to the International Food Policy Research Institute (IFPRI), Statistics South Africa (STATSSA), Trade and Industrial Policy Strategy of South Africa (TIPS) and the Department of Water Affairs and Forestry (DWAF), for the use of their different data sources; and to the African Economic Research Consortium (AERC), United States Agency for International Development (USAID) and the University of Colorado, Boulder, for jointly funding the study.

\section{References}

Chitiga, M. \& Mabugu, R. (2006). Evalauting the impact of land redistribution : A CGE microsimulation application to Zimbabwe. University of Pretoria, Department of Economics working paper 2006-09. www.up.ac.za/web/ea/academic/ economics/index.html

Department of Water Affairs and Forestry (DWAF) (2004). Towards a Framework for Water Allocation Planning: A draft position paper for water allocation reform in South Africa. Water Allocations Directorate, DWAF, Pretoria, South Africa.

Rosegrant, M. W., Cai, X. \& Cline, S. A. (2003). World water and food to 2025: Dealing with scarcity. International Food Policy Research Institute, Washington D.C.

Rutherford, R. T. (1995). Applied General Equilibrium Modeling with MPSGE as a GAMS Subsystem: An overview of the Modelling Framework and Syntax Department of Economics. Working Paper, University of Colorado. Available at www.gams.com/solvers/mpsge/syntax.htm.

Statistics South Africa (STATSSA) (2004). Natural resource accounts: Water accounts for nineteen water management areas. Report No. 04-05-01 (2000), STATSSA, Pretoria, South Africa.

Strzepek, K. M. \& Carbone, J. (2007). A CGE model for South Africa with explicit modelling of water as a factor of production. Department of Civil, Environmental and Architectural Engineering working paper 2007-22, University of Colorado.

Thurlow, J. \& van Seventer, D. E. N. (2002). A standard computable general equilibrium model for South Africa. Trade and Macroeconomics Division Paper No.100, International Food Policy Research Institute, Washington DC and Trade and Industrial Policy Strategies, Johannesburg, South Africa.

Trade and Industrial Policy Secretariat (TIPS) (2004). Online resources for trade and industrial policy research in South Africa: South African economic indicators. Trade and Industrial Policy Secretariat, Pretoria, South Africa Available at, www.Tips.org.za 


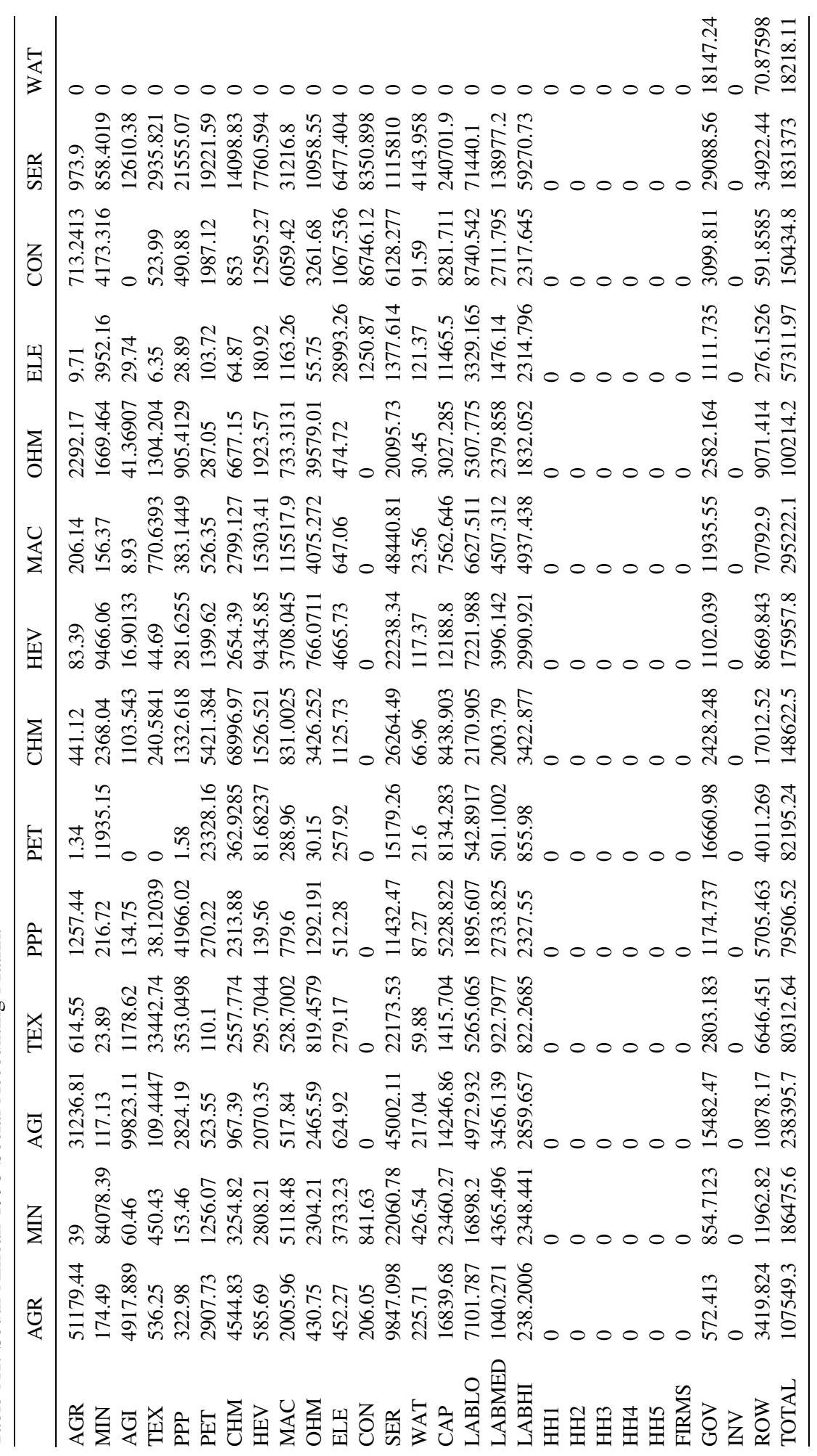




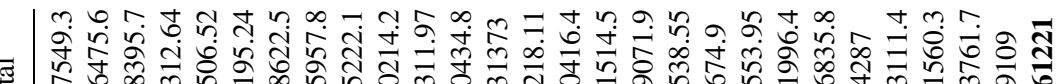

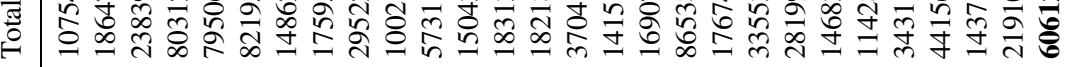

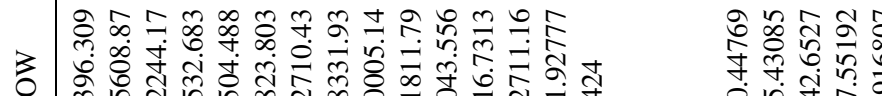

О 슬 $\infty$ \&

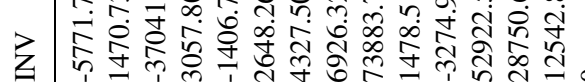

- m

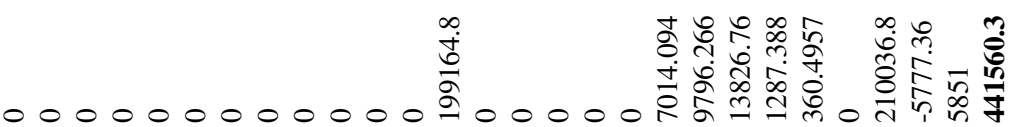
$000000000000-00000 \frac{1}{2}-100 \mathrm{~min}$ 000000000000000000 岗

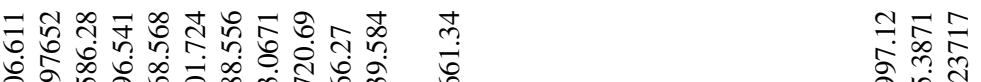

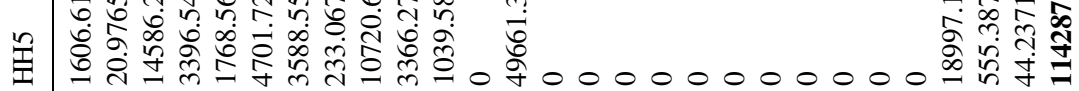
行 范

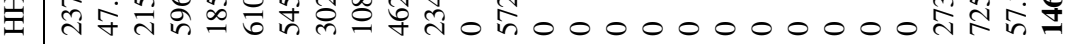

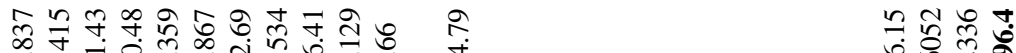

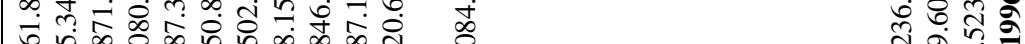
胫

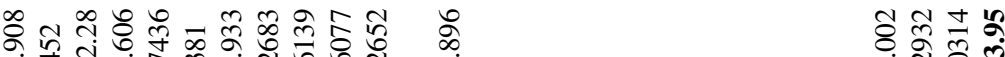

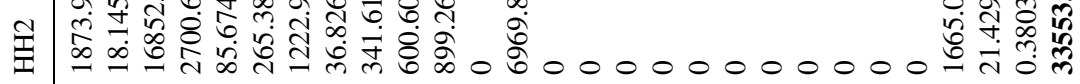

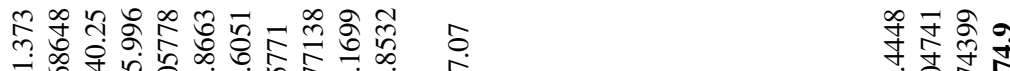

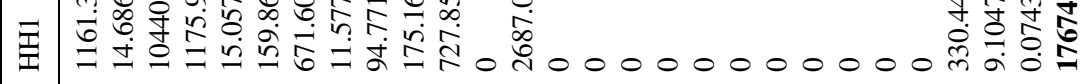

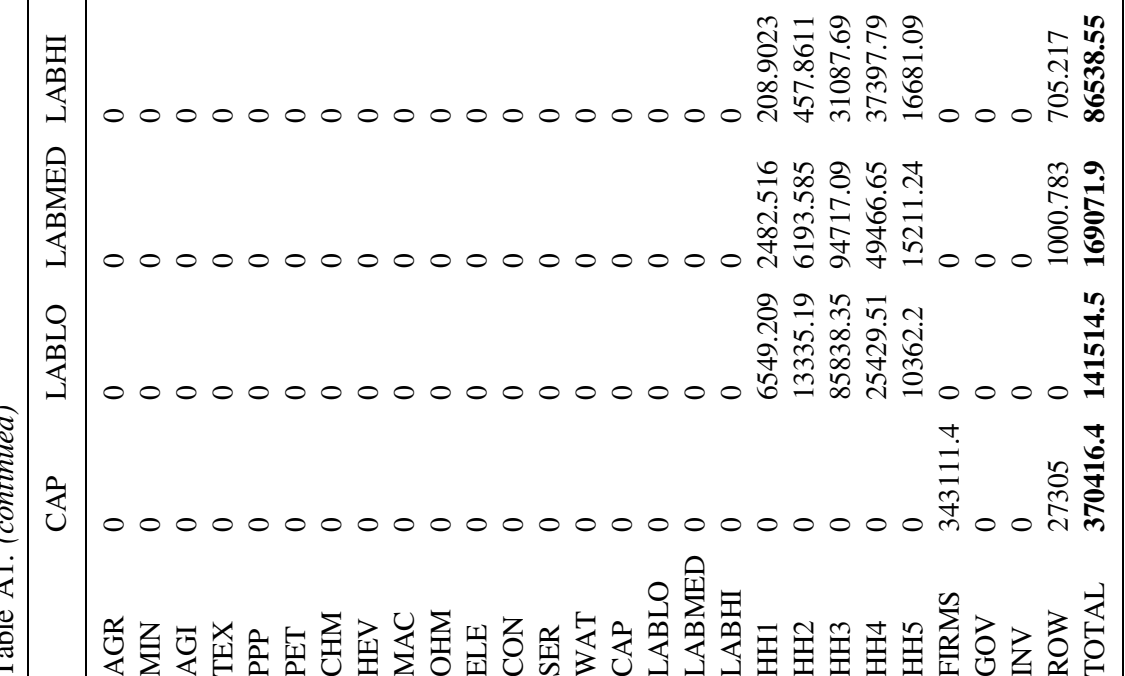




\section{KEY FOR THE SAM}

\section{PRODUCTION SECTOR}

AGR Agriculture

MIN: Mining

AGI: Agricultural Manufacturing

TEX: Clothing and Textile

PPP: Pulp and Paper Manufacturing

PET: Petrol Chemical Manufacturing

CHM: Other Chemical Manufacturing

HEV: Heavy Manufacturing

MAC: Machinery and Equipments Manufacturing

OHM: Other Manufacturing

CON: Construction

ELE: Electricity

SER: Services

\section{FACTORS OF PRODUCTION}

WAT: Water

CAP: Cap

LABLO: Unskilled Labour

LABMED: Medium Skilled Labour

LABHI: High Skilled Labour

\section{HOUSEHOLD CATEGORIES}

HH1: Least Income Households

HH2: Low Income Households

HH3: Middle Income Households

HH4: High Income Households

HH5: Highest Income Households

\section{OTHER INSTITUTIONS}

FIRMS: Firms

GOV: Government

ROW: Rest of the World

INVESTMENT

INV: Investment 